\title{
Dopplerographic Evaluation of Blood Flow Parameters in Vertebral Arteries in Patients with Cervicogenic Headache in the Presence of Uncovertebral Arthrosis
}

\author{
Abdullaiev RY1*, Kalashnikov VI1, Posokhov NF² and Kostyukovskaya \\ $\mathrm{AE}^{1}$ \\ ${ }^{1}$ Kharkiv Medical Academy of Postgraduate Education, Ukraine \\ ${ }^{2}$ Institute of Neurology, Psychiatry and Narcology, National Academy of Medical Sciences \\ of Ukraine, State Institution, Ukraine
}

Research Article

Volume 2 Issue 2

Received Date: March 23, 2018

Published Date: April 19, 2018

DOI: $10.23880 / \mathrm{mjccs}-16000146$

*Corresponding author: Rizvan Yagubovich Abdullaiev, Kharkiv Medical Academy of Postgraduate Education, Ukraine, Email: r.abdullaev@bk.ru

\section{Abstract}

Introduction: Cervicogenic headache $(\mathrm{CH})$ - one of the most common, is due to biomechanical dysfunction of the cervical vertebral motor segments. It accounts for $15-20 \%$ of all headaches. According to International Classification of HeadacheRelated Disorders (ICHRD-3 beta, 2013) CH is a headache caused by a lesion of the neck (bone structures, disc and / or soft tissues) and is usually accompanied by pain in the neck. The unilateral character of the headache without changing sides, the provocation of a typical image of pain by external pressure on the muscles of the neck or movement of the cervical spine, the spread of pain from the occipital region to frontotemporal, are most characteristic of $\mathrm{CH}$.

Objective: Dopplerographic evaluation of blood flow parameters in vertebral arteries in patients with cervicogenic headache, diagnosed with arthrosis of the uncover vertebral and atlanto-axial articulations.

Materials and methods: A retrospective analysis of the results of Doppler ultrasound in the 2nd and 3rd segments of the vertebral artery (VA) was performed in 43 patients aged 23-39 years, who had X-ray and MRI diagnosed arthrosis of the uncovertebral junction at the level of $\mathrm{C} 2-\mathrm{C} 3$ to $\mathrm{C} 4-\mathrm{C} 5$; among them the instability of one of the upper cervical vertebrae was noted in 21 cases. Among the examined were 26 men and 17 women. The maximum systolic velocity (Vs), the end diastolic velocity (Vd), the resistance index (RI) in second and third segments of VA in the neutral spine and flexion position of the neck were determined. The control group consisted of 24 people aged 18-35 years without chronic headache, absence of arthrosis of the uncovertebral joints according to the results of X-ray or MRI. Dopplerography was 


\section{Medical Journal of Clinical Trials \& Case Studies}

conducted on a Philips HD 11XE device using a linear and micro convection transducers in the frequency range $5-10 \mathrm{MHz}$ and 4-9 MHz; MRI - General Electric, Signa HDI, 1.5T

Results: In patients with uncovertebral arthrosis at the level of C5-C6, Vs and RI did not differ from the norm and amounted to $53.7 \pm 6.1 \mathrm{~cm} / \mathrm{s}, \mathrm{RI}-0.59 \pm 0.03$; at the level of C2-C3 $-42.9 \pm 5.3 \mathrm{~cm} / \mathrm{s}, \mathrm{RI}-0.62 \pm 0.03$. When the head turned to the side at the $\mathrm{C} 2$-C3 level, a significant $(\mathrm{P}<0.05)$ decrease in Vs was observed up to $34.7 \pm 5.9 \mathrm{~cm} / \mathrm{s}$ and an increase in RI to $0.69 \pm 0.04$. In patients with uncovertebral arthrosis in combination with instability of the upper cervical vertebrae at the level of C5-C6, Vs and RI amounted to $51.4 \pm 5.8 \mathrm{~cm} / \mathrm{s}$, RI $-0.58 \pm 0.03$; at the level of C2-C3 - $38.5 \pm 5.7 \mathrm{~cm} / \mathrm{s}$, RI $0.62 \pm 0.03$. When the head turned to the side at the $\mathrm{C} 2$-C3 level, a significant $(\mathrm{P}<0.01)$ decrease in Vs was observed up to $27.6 \pm 4.8 \mathrm{~cm} / \mathrm{s}$ and an increase in RI to $0.71 \pm 0.04$. When the head was turned to the side in patients with instability of the upper cervical vertebrae and unkorvertebral arthrosis, Vs was significantly lower compared to the control group $(27.6 \pm 4.8 \mathrm{~cm} / \mathrm{s}$ and $42.6 \pm 4.7 \mathrm{~cm} / \mathrm{s} ; \mathrm{P}<0.05)$.

Conclusion: Uncovertebral arthrosis in combination with the instability of the upper cervical vertebrae is one of the common causes of cervicogenic headache. The main pathogenetic mechanism is changes in blood flow at the border of the second and third segments of the vertebral arteries, especially after rotational movements.

Keywords: Cervicogenic Headache; Dopplerography; Vertebral Artery; Uncovertebral Arthrosis; Instability of the Upper Cervical Vertebrae

Abbreviations: CH: Cervicogenic Headache; ICHRD: International Classification of Headache-Related Disorders; VA: Vertebral Artery; RI: Resistance Index; CHISG: Cervicogenic Headache International Study Group Criteria; HIS: International Headache Society; TSM: Translatoric Spinal Manipulation; LD: Lumen Diameter.

\section{Introduction}

Cervicogenic Headache International Study Group Criteria (CHISG) include producing or aggravating the patient's familiar headache by any of the following: 1) neck movement, 2) sustained awkward head positioning or 3) by a combination of external pressure over the upper cervical/ occipital region on the symptomatic side associated with restriction of neck range of motion. Cervicogenic Headache often occurs as a result of tension in the muscles of the neck. Many factors can cause tension headaches, such as missing food, lack of sleep, overwork, working in front of the computer for a long period of time, overstuffing, prolonged uncomfortable position of the neck in a dream [1].
The leading pathogenetic mechanism of CGD development is a change in the mobility of the three upper cervical segments (C0-C3), which exerts a reflex influence on the trigeminal-cervical nucleus. The pain that the patient feels in the region of the head and neck arises as a result of processing the information obtained by this nucleus. The latter includes afferent neurons from the trigeminal nerve, C1-C3 spinal nerves, and additional afferents from VII, IX, and X cranial nerves. The leading role in the formation of the central nervous system is played by the irritation of the vegetative plexus of the vertebral arteries.

Cervicogenic headache is a syndrome characterized by chronic hemicranial pain that is referred to the head from either bony structures or soft tissues of the neck. The trigeminocervical nucleus is a region of the upper cervical spinal cord where sensory nerve fibers in the descending tract of the trigeminal nerve (trigeminal nucleus caudalis) are believed to interact with sensory fibers from the upper cervical roots. This functional convergence of upper cervical and trigeminal sensory pathways allows 


\section{Medical Journal of Clinical Trials \& Case Studies}

the bidirectional referral of painful sensations between the neck and trigeminal sensory receptive fields of the face and head. A functional convergence of sensorimotor fibers in the spinal accessory nerve (CN XI) and upper cervical nerve roots ultimately converge with the descending tract of the trigeminal nerve and might also be responsible for the referral of cervical pain to the head [2].

There is a significant lack of agreement in the definition of the diagnosis of cervicogenic headache. The IHS diagnostic criteria rely, at least in part, on a patient's response to diagnostic facet injection blocks. Controlled diagnostic blocks into the cervical facet joints are invasive, expensive and not readily available, and so they cannot be considered as useful in most practitioners' offices. Despite questions of diagnostic accuracy, the clinical features of CGH from the CHISG checklist provide a readily available, safe and inexpensive approach to diagnosis that is particularly useful in manual therapy. Merging the International Headache Society IHS and the Cervicogenic Headache International Study Group (CHISG) критерия helped improve the diagnosis of cervicogenic headaches [3].

The traditional diagnosis method of cervical spondylosis is based on X-ray reading. Based on an analysis of 1034 clinical cases and 60 cases of a test group using digital radiography $\mathrm{Yu} \mathrm{X}$, et al. increased the diagnostic efficiency of up to $80 \%$ of cervical spondylosis compared with conventional radiography, which diagnosed spondylosis in $68.3 \%$ of cases [4]. Doppler ultrasound imaging is a noninvasive and useful modality for the examination of vertebral arteries. Color duplex/Doppler ultrasound is considered to provide a valid and reliable noninvasive measurement of vertebral arterial blood flow velocity. There is evidence that Doppler ultrasound measures of vertebral artery blood flow may be sufficiently responsive to detect changes in cervical rotations or after intervention. It has been reported that a decrease in vertebral artery blood flow could be identified by Doppler ultrasound at both upper and lower cervical levels during end-range cervical rotation in asymptomatic participants. This indicated that Doppler ultrasound would be able to detect changes in the vertebral arterial blood flow velocities decreased when the vertebral arteries are under stress from compression or stretching. Doppler ultrasound has also been used to detect improvement in vertebral arterial blood flow velocities in patients with vertebrobasilar artery insufficiency before and after medical intervention [5-9].
Cervicogenic dizziness is characterized by symptoms of imbalance or spinning associated with neck pain, stiffness or headache. Mechanical compression, tension, dissection, or stenosis of 1 of both vertebral arteries as they pass through the cervical region may reduce blood flow and thus result in symptoms of dizziness. Poor head and neck posture and malalignment of the upper cervical spine are among the causes of the mechanical compromise that could result in decreased vertebrobasilar blood flow velocity and lead to dizziness. The results of study of Shum G. L. et al. provide evidence to support the use of Doppler ultrasound in investigating the role of vertebral arteries in management of cervicogenic dizziness [10].

Objective: Dopplerographic evaluation of blood flow parameters in vertebral arteries in patients with cervicogenic headache, diagnosed with arthrosis of the uncoververtebral junction.

\section{Materials and Methods}

A retrospective analysis of the results of Doppler ultrasound in the 2nd and 3rd segments of the vertebral artery (VA) was performed in 43 patients aged 23-39 years, who had X-ray and MRI diagnosed arthrosis of the uncovertebral junction at the level of $\mathrm{C} 2-\mathrm{C} 3$ to $\mathrm{C} 4-\mathrm{C} 5$; among them the instability of one of the upper cervical vertebrae was noted in 21 cases. Among the examined were 26 men and 17 women. The maximum systolic velocity (Vs), the end diastolic velocity (Vd), the resistance index (RI) in second and third segments of VA in the neutral spine and flexion position of the neck were determined. The control group consisted of 24 people aged 18-35 years without chronic headache, absence of arthrosis of the uncovertebral joints according to the results of X-ray or MRI. Dopplerography was conducted on a Philips HD 11XE device using a linear and micro convection transducers in the frequency range $5-10 \mathrm{MHz}$ and 4-9 MHz; MRI - General Electric, Signa HDI, 1.5T.

\section{Results}

In all subjects, the Doppler blood flow spectrum was recorded in the second segment at the C5-C6 and C2-C3 levels in the neutral position on the back, and also with the head turning to the side. In the control group in the second segment of the VA, Vs was $49.6 \pm 5.4 \mathrm{~cm} / \mathrm{s}$, RI $0.61 \pm 0.03$; at the level of $\mathrm{C} 2-\mathrm{C} 3-50.2 \pm 5.1 \mathrm{~cm} / \mathrm{s}$, RI $0.58 \pm 0.03$; when the head is rotated at C2-C3 level -42.6 $\pm 4.7 \mathrm{~cm} / \mathrm{s}, \mathrm{RI}-0.63 \pm 0.03$, respectively (Figures $1 \& 2$ ). 


\section{Medical Journal of Clinical Trials \& Case Studies}

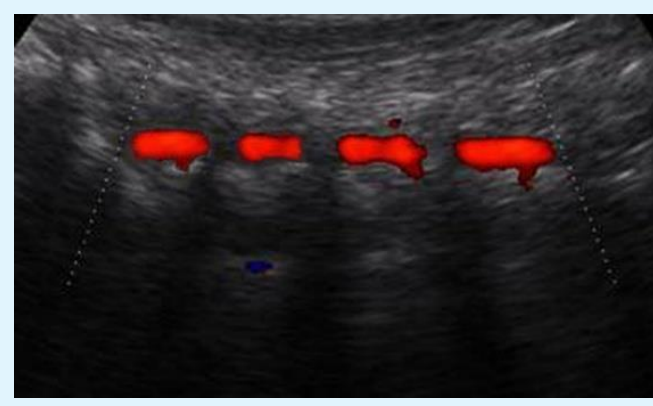

Figure 1: Color Doppler view of the normal vertebral artery at the level of C3-C6.

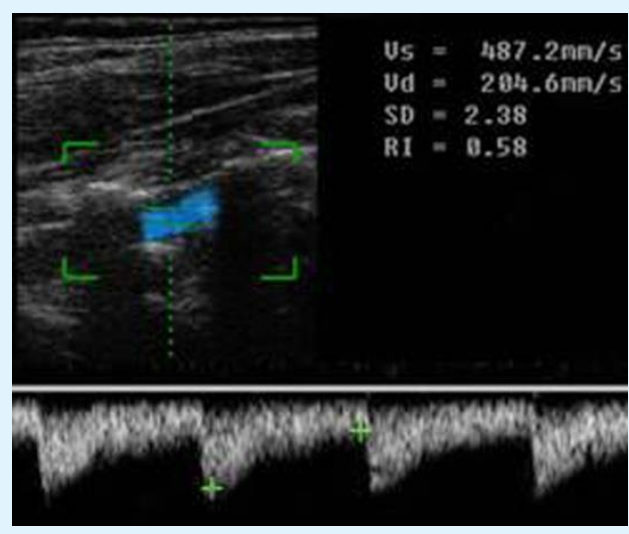

Figure 2: Doppler spectrum of the normal blood flow in the second segment of the vertebral artery at the level of C5-C6. The Vs is $48,7 \mathrm{~cm} / \mathrm{c}, \mathrm{RI}-0,58$.

\begin{tabular}{|c|c|c|c|c|c|c|}
\hline \multirow{2}{*}{$\begin{array}{c}\text { Doppler } \\
\text { parameters }\end{array}$} & \multicolumn{3}{|c|}{$\begin{array}{c}\text { Patients with Uncovertebral Arthrosis } \\
\text { without instability of the C2-C4 (n=22) }\end{array}$} & \multicolumn{3}{c|}{ Control group (n=24) } \\
\cline { 2 - 7 } & $\begin{array}{c}\text { II Segment } \\
\text { of VA C5-C6 } \\
\mathbf{1}\end{array}$ & $\begin{array}{c}\text { II Segment } \\
\text { of VA C2-C3 } \\
\mathbf{2}\end{array}$ & $\begin{array}{c}\text { Neck Flexion } \\
\mathbf{3}\end{array}$ & $\begin{array}{c}\text { II Segment } \\
\text { of VA C5-C6 } \\
\mathbf{1}\end{array}$ & $\begin{array}{c}\text { II Segment } \\
\text { of VA C2-C3 } \\
\mathbf{2}\end{array}$ & $\begin{array}{c}\text { Head } \\
\text { rotated } \\
\mathbf{3}\end{array}$ \\
\hline Vs (cm/c) & $\begin{array}{c}53,7 \pm 6,1 \\
\mathrm{P} 1-3<0,05\end{array}$ & $42,9 \pm 5,3$ & $34,7 \pm 5,9$ & $49,6 \pm 5,4$ & $50,2 \pm 5,1$ & $42,6 \pm 4,7$ \\
\hline RI & $0,59 \pm 0,03$ & $0,62 \pm 0,03$ & $\begin{array}{c}0,69 \pm 0,04 \\
\text { P3-1<0,05 }\end{array}$ & $0,61 \pm 0,03$ & $0,58 \pm 0,03$ & $0,63 \pm 0,03$ \\
\hline
\end{tabular}

Table 1: Doppler parameters in patients with Uncovertebral Arthrosis without instability of the upper cervical vertebrae.

In patients with uncovertebral arthrosis at the level of C5-C6, Vs and RI did not differ from the norm and amounted to $53.7 \pm 6.1 \mathrm{~cm} / \mathrm{s}, \mathrm{RI}-0.59 \pm 0.03$; at the level of C2-C3 - 42.9 $\pm 5.3 \mathrm{~cm} / \mathrm{s}, \mathrm{RI}-0.62 \pm 0.03$. When the head turned to the side at the C2-C3 level, a significant (P $<0.05$ ) decrease in Vs was observed up to $34.7 \pm 5.9 \mathrm{~cm} / \mathrm{s}$ and an increase in RI to $0.69 \pm 0.04$ (Table 1).

Dopplerometric parameters of blood flow in patients with uncovertebral arthrosis in combination with instability of the upper cervical vertebrae are presented in Table 2. In this patient at the level of C5-C6, Vs and RI amounted to $51.4 \pm 5.8 \mathrm{~cm} / \mathrm{s}, \mathrm{RI}-0.58 \pm 0.03$; at the level of $\mathrm{C} 2-\mathrm{C} 3-38.5 \pm 5.7 \mathrm{~cm} / \mathrm{s}, \mathrm{RI}-0.62 \pm 0.03$. When the head turned to the side at the C2-C3 level, a significant (P $<0.01$ ) decrease in Vs was observed up to $27.6 \pm 4.8 \mathrm{~cm} / \mathrm{s}$ and an increase in RI to $0.71 \pm 0.04$ (Figures $3-5$ ). When the head was turned to the side in patients with instability of the upper cervical vertebrae and unkorvertebral arthrosis, Vs was significantly lower compared to the control group $(27.6 \pm 4.8 \mathrm{~cm} / \mathrm{s}$ and $42.6 \pm 4.7 \mathrm{~cm} / \mathrm{s}$; $\mathrm{P}<0.05)$.

\begin{tabular}{|c|c|c|c|c|c|c|}
\hline \multirow{2}{*}{$\begin{array}{c}\text { Doppler } \\
\text { parameters }\end{array}$} & \multicolumn{2}{|c|}{$\begin{array}{c}\text { Patients with uncovertebral arthrosis and } \\
\text { instability of the C2-C4 (n=21) }\end{array}$} & \multicolumn{3}{c|}{ Control group } \\
\cline { 2 - 7 } & $\begin{array}{c}\text { II Segment } \\
\text { of VA C5-C6 } \\
\mathbf{1}\end{array}$ & $\begin{array}{c}\text { II Segment } \\
\text { of VA C2-C3 } \\
\mathbf{2}\end{array}$ & $\begin{array}{c}\text { Neck Flexion } \\
\mathbf{3}\end{array}$ & $\begin{array}{c}\text { II Segment } \\
\text { of VA C5-C6 } \\
\mathbf{1}\end{array}$ & $\begin{array}{c}\text { II Segment } \\
\text { of VA C2-C3 } \\
\mathbf{2}\end{array}$ & $\begin{array}{c}\text { Head rotated } \\
\mathbf{3}\end{array}$ \\
\hline Vs (cm/c) & $\begin{array}{c}51,4 \pm 5,8 \\
\mathrm{P} 1-3<0,01\end{array}$ & $38,5 \pm 5,7$ & $\begin{array}{c}27,6 \pm 4,8 \\
\mathrm{P} 3-3<0,05\end{array}$ & $49,6 \pm 5,4$ & $50,2 \pm 5,1$ & $42,6 \pm 4,7$ \\
\hline RI & $0,58 \pm 0,03$ & $0,62 \pm 0,03$ & $\begin{array}{c}0,71 \pm 0,04 \\
\mathrm{P} 1-3<0,05\end{array}$ & $0,61 \pm 0,03$ & $0,58 \pm 0,03$ & $0,63 \pm 0,03$ \\
\hline
\end{tabular}

Table 2: Doppler parameters in patients with Uncovertebral Arthrosis and instability of the upper cervical vertebrae. 


\section{Medical Journal of Clinical Trials \& Case Studies}

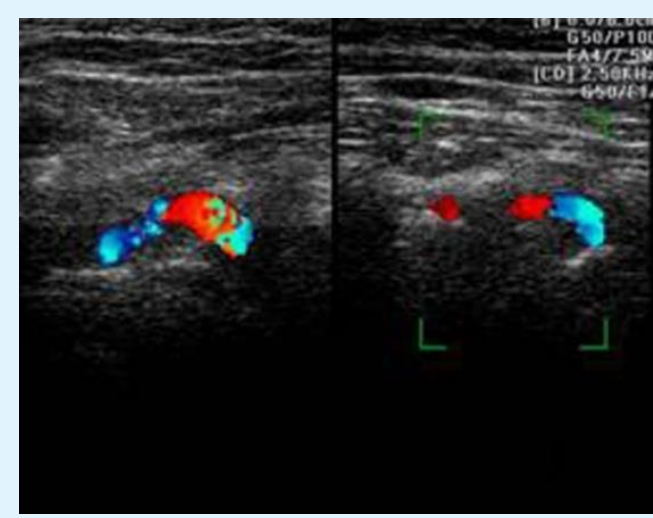

Figure 3: Color Doppler view of the vertebral artery at the level of C3-C4 and C4-C5.

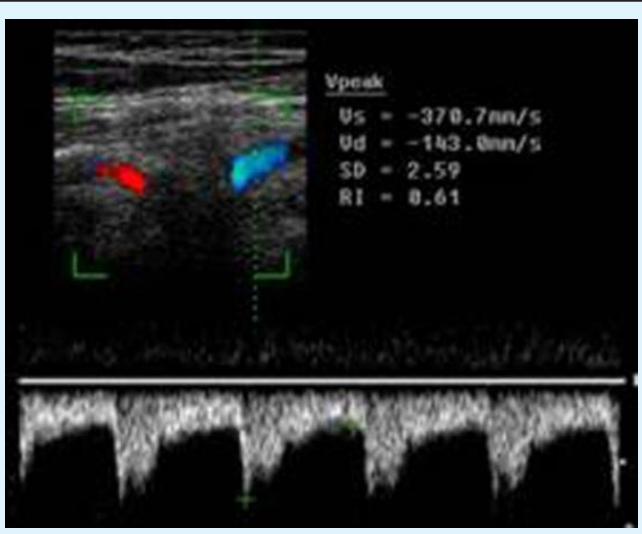

Figure 4: Doppler spectrum of the blood flow at level of C3-C4 in a patient with instability of C3.

At the level of C3-C4, the direction of the blood flow is different - indicated by different colors.

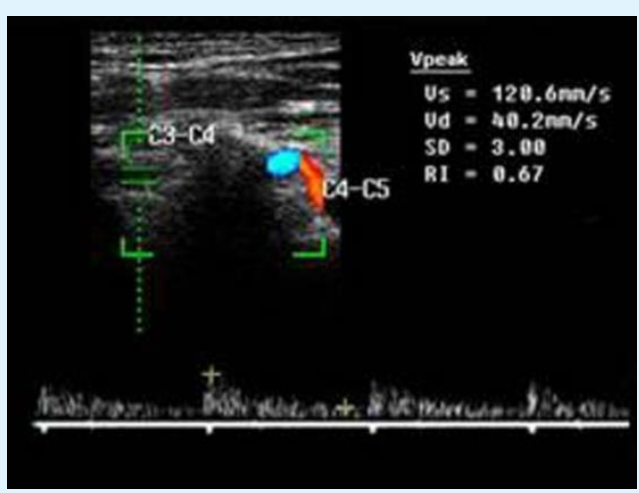

Figure 5: Doppler spectrum of the blood flow in second segment of the vertebral artery at the level of C3-C4 in a patient with uncovertebral arthrosis and C3 instability at a flexion of the neck. The Vs decreased to $12 \mathrm{~cm} / \mathrm{c}, \mathrm{RI}$ increased to 0,67 .

\section{Discussion}

Creighton D. et al. has determined the effect of three C5-C6 non-thrust translatoric spinal manipulation (TSM) techniques on vertebral artery (VA) lumen diameter (LD) and two blood flow velocity parameters. The two-tailed research hypothesis was that the TSM techniques would result in a significant change (increase or decrease) in blood flow velocity and arterial LD at the C5-C6 intertransverse portion of the VA. This study has provided evidence for the safety of the three lower cervical nonthrust TSM techniques on the current population studied [11]. Bulut MD, et al. studied blood flow in vertebral arteries in patients with lordosis of the cervical vertebrae and revealed significant changes in the parameters of Dopplerometry in functional samples. Our studies showed statistically significant changes in the parameters of the dopplerometry of vertebral arteries in patients with uncovertebral arthrosis in combination with the instability of the upper cervical vertebrae [12]. This data opens up new opportunities to use them for manual therapy.

\section{Conclusion}

Unco-vertebral arthrosis in combination with the instability of the upper cervical vertebrae is one of the common causes of cervicogenic headache. The main pathogenetic mechanism is changes in blood flow at the border of the second and third segments of the vertebral arteries, especially after rotational movements.

\section{References}

1. Headache Classification Subcommittee of the International Headache Society (2004) The International Classification of Headache Disorders. $2^{\text {nd }}($ Edn.). Cephalalgia 1: 9-160.

2. Bogduk N, Govind J (2009) Cervicogenic headache: an assessment of the evidence on clinical diagnosis, invasive tests, and treatment. Lancet Neurol 8(10): 959-968.

3. Becker WJ (2010) Cervicogenic headache: evidence that the neck is a pain generator. Headache 50(4): 699-705.

4. Yu X, Liu M, Meng L, Xiang L (2015) Classifying cervical spondylosis based on X-ray quantitative diagnosis. Neurocomputing 165: 222-227. 


\section{Medical Journal of Clinical Trials \& Case Studies}

5. Mitchell J (2007) Doppler insonation of vertebral artery blood flow changes associated with cervical spine rotation: Implications for manual therapists. Physiother Theory Pract 23(6): 303-313.

6. Bozgeyik Z, Berilgen S, Ozdemir H, Tekatas A, Ogur E (2008) Evaluation of the effects of sildenafil citrate (Viagra) on vertebral artery blood flow in patients with vertebro-basilar insufficiency. Korean J Radiol $9(6): 477-480$.

7. Mitchell J (2009) Vertebral artery blood flow velocity changes associated with cervical spine rotation: a meta-analysis of the evidence with implications for professional practice. J Man Manip Ther 17(1): 46-57.

8. Abdullaiev R Ya, Marchenko VG, Dzyak LA, et al. (2010) Ultrasonography in Neurology. Kharkov: Nove word, pp: 152.
9. Yurdacul S, Aytekin S (2011) Doppler ultrasound imaging of the carotid and vertebral arteries. Turk Kardiyol Dern Ars 39(6): 508-517.

10. Shum G, Cinnamond S, Hough D, Choy S, Whittingham W (2017) Doppler ultrasonography assessment of the vertebral artery in people with cervicogenic dizziness. J Spine 6: 4.

11. Creighton D, Kondratek M, Krauss J, Huijbregts P, Qu $H$ (2011) Ultrasound analysis of the vertebral artery during non-thrust cervical translatoric spinal manipulation. Journal of Manual and Manipulative Therapy 19(2): 84-90.

12. Bulut MD, Alpayci M, Senkoy E, Bora A, Yazmalar L, et al. (2016) Decreased Vertebral Artery Hemodynamics in Patients with Loss of Cervical Lordosis. Med Sci Monit 22: 495-500. 